\title{
Cognitive Digital Twins for Resilience in Production: A Conceptual Framework
}

\author{
Pavlos Eirinakis ${ }^{1} \oplus$, Stavros Lounis ${ }^{2, *}$, Stathis Plitsos ${ }^{1}$, George Arampatzis ${ }^{3}{ }^{\circledR}$, Kostas Kalaboukas ${ }^{4}{ }^{\oplus}$, \\ Klemen Kenda ${ }^{5}{ }^{\circledR}$, Jinzhi Lu ${ }^{6}{ }^{\circ}$, Jože M. Rožanec ${ }^{7}{ }^{\circledR}$ and Nenad Stojanovic ${ }^{8}$
}

check for updates

Citation: Eirinakis, P.; Lounis, S.;

Plitsos, S.; Arampatzis, G.;

Kalaboukas, K.; Kenda, K.; Lu, J.;

Rožanec, J.M.; Stojanovic, N.

Cognitive Digital Twins for Resilience

in Production: A Conceptual

Framework. Information 2022, 13, 33.

https://doi.org/10.3390/

info13010033

Academic Editor: Willy Susilo

Received: 15 November 2021

Accepted: 10 January 2022

Published: 12 January 2022

Publisher's Note: MDPI stays neutral with regard to jurisdictional claims in published maps and institutional affiliations.

Copyright: (c) 2022 by the authors. Licensee MDPI, Basel, Switzerland. This article is an open access article distributed under the terms and conditions of the Creative Commons Attribution (CC BY) license (https:// creativecommons.org/licenses/by/ $4.0 /)$.
1 Laboratory of Production Management Information Systems, Department of Industrial Management and Technology, University of Piraeus, Karaoli and Dimitriou 80, 18534 Piraeus, Greece; pavlose@unipi.gr (P.E.); stathis.plitsos@aueb.gr (S.P.)

2 ELTRUN-E-Business Research Center, Department of Management Science and Technology, Athens University of Economics and Business, Patission 76, 10434 Athens, Greece

3 School of Production Engineering and Management, Technical University of Crete, 73100 Chania, Greece; garampatzis@pem.tuc.gr

4 Gruppo Maggioli-Greek Branch, 19 Andrea Papandreou str., 15124 Marousi, Greece; kostas.kalaboukas@maggioli.gr

5 Qlector d.o.o., Rovšnikova 7, 1000 Ljubljana, Slovenia; klemen.kenda@qlector.com

6 EPFL SCI-STI-DK, Station 9, CH-1015 Lausanne, Switzerland; jinzhi.lu@epfl.ch

7 Jožef Stefan International Postgraduate School, Jamova 39, 1000 Ljubljana, Slovenia; joze.rozanec@ijs.si

8 Nissatech, Cara Dusana 58,18000 Nis, Serbia; nenad.stojanovic@nissatech.com

* Correspondence: slounis@aueb.gr

\begin{abstract}
Digital Twins (DTs) are a core enabler of Industry 4.0 in manufacturing. Cognitive Digital Twins (CDTs), as an evolution, utilize services and tools towards enabling human-like cognitive capabilities in DTs. This paper proposes a conceptual framework for implementing CDTs to support resilience in production, i.e., to enable manufacturing systems to identify and handle anomalies and disruptive events in production processes and to support decisions to alleviate their consequences. Through analyzing five real-life production cases in different industries, similarities and differences in their corresponding needs are identified. Moreover, a connection between resilience and cognition is established. Further, a conceptual architecture is proposed that maps the tools materializing cognition within the DT core together with a cognitive process that enables resilience in production by utilizing CDTs.
\end{abstract}

Keywords: digital twin; cognitive manufacturing; resilient manufacturing; industry 4.0; ISO 23247; optimization; simulation; knowledge graph

\section{Introduction and Motivation}

Unexpected disruptive events may interrupt normal production conditions and cause production loss. Recent disruptions caused by the COVID-19 pandemic or the implications of the emerging climate crisis have further exemplified that a new form of operations is required to empower manufacturing organizations with readiness against external or internal disruptive events, enabling them to swiftly adjust in an appropriate manner. In this regard, a resilient manufacturing system should incorporate the capability to suffer minimum production loss during disruptions and to recover to a steady state quickly after each disruption [1]. To achieve this new form of operations, situation-aware manufacturing systems [2] should perceive and comprehend the current state of the production process to identify disruptions and project it into the future to evaluate their impact, supporting informed decision making and eventually enabling the appropriate response.

Meanwhile, traditional manufacturing is in the throes of the digital transformation brought about by Industry 4.0 enabling technologies. Digital infrastructure and Internet of Things (IoT) connectivity enable the continuous monitoring of physical manufacturing 
entities. By blending the real and the virtual production world, it is now possible to connect all parts related to the production process: machines, products, systems and people. In this regard, Digital Twins (DTs) have steadily been gaining ground in research and practice [3-5]. The concept of a DT was introduced by Grieves [6], having in its basic form its three parts, "(a) physical products in Real Space, (b) virtual products in Virtual Space, and (c) the connection of data and information that ties the virtual and real products together". Since then, it evolved and has been given several different definitions (e.g., see a detailed discussion in [7] (Section 3.1)). A DT in manufacturing can have multiple applications, as it can reflect different levels of granularity, such as a machine, a process, a whole production line or production environment, a shop floor or even a supply chain. Since its inception, its rapid uptake has led to extensions of the concept that incorporate data and services [8]. In that regard, the virtualization and subsequent twinning of the physical and virtual in the manufacturing sector has led to the creation of various new system capabilities $[7,9,10]$, with predominant ones being visibility, simulation, optimization and control of production processes. The rapid uptake of DTs has led to the need for standardization efforts, hence the ISO 23247 Digital Twin framework for manufacturing [11].

DTs have moved from concept to reality much faster than expected, primarily by utilizing complex numerical models that reflect the behavior of a physical entity. However, with real-time production data becoming a commodity, physical asset virtualization is no longer a static and design-time process. By incorporating data-driven models, it has become a dynamic, run-time process that may continuously adapt the behavioral model of the digital counterpart to mirror the behavior of the physical element. Based on this data-driven approach, DTs have further evolved by incorporating fundamental aspects of cognition, such as "attention (selective focus), perception (forming useful precepts from raw sensory data), memory (encoding and retrieval of knowledge), reasoning (drawing inferences from observations, beliefs, and models), learning (from experiences, observations, and teachers), problem-solving (achieving goals)" [9], thus giving rise to Cognitive Digital Twins (CDTs) $[9,12,13]$. Through incorporating services that enable cognition, CDTs offer the ability to monitor the current status of the corresponding manufacturing elements, identify (or even predict) anomalies in production and explore their root-cause and in turn calculate, evaluate and hence support decisions on possible actions for the appropriate (optimized) response towards mitigating the consequences of the corresponding disruptions.

This paper proposes a conceptual framework for implementing the cognition for DTs of production processes towards achieving resilience in production. This entails identifying/predicting anomalies and events (perception), focusing on handling them (attention), retrieving the appropriate information (memory), understanding and identifying their root-cause (reasoning), producing and evaluating alternative courses of action (problemsolving) and incorporating information relevant to the situation (learning). To that end, the paper provides a mapping between the operational needs of five industrial cases on decision support within their production operations with the corresponding cognitive capabilities of DTs and the suggested tools to materialize them. These tools are incorporated within a conceptual architecture that is based on ISO 23247 while also providing the corresponding cognitive process for anomaly detection and handling. The five real-life cases examined arise from different industries (oil refineries, waste-to-fuel transformation, electronics' production for the automotive industry, steel processing and the textile industry) and offer a wide spectrum of production processes and corresponding events, from Liquefied Petroleum Gas (LPG) off-specs production recovery to production scheduling with predictive maintenance, and from taking into account disruptions caused by machine malfunctions or material failure to crane movement and to facilitating new urgent orders. The breadth and depth of the involved cases (as derived by their analysis in the scope of an EU-funded research project) provide a wide range of settings that includes both process industries and manufacturers, both technologically advanced factories as well as factories utilizing legacy systems, and a wide variety of disruptive events that need to be handled. 
The remainder of the paper is structured as follows. Section 2 examines the concept of cognition within the manufacturing context. Section 3 presents five industrial cases and the corresponding needs for handling disruptive events in production. Section 4 examines how resilience in production can be achieved through cognitive capabilities of CDTs. Section 5 presents a conceptual architecture for CDTs based on ISO 23247, mapping cognition and its corresponding services and tools within the core of the DT. Moreover, it presents how the cognition process of CDTs offers pathways to production systems for handling disruptions. Section 6 provides a discussion on our findings, and Section 7 concludes the paper by offering avenues for future research.

\section{Cognition in Manufacturing}

Cognition in manufacturing is mainly inspired by human cognition as a reaction to the stimuli that it receives and the actions it takes. The main capabilities related to cognition include perception, attention, memory, reasoning, problem-solving and learning [9]. Perception refers to "the process of selecting, organizing, and interpreting sensory data into a usable mental representation of the world" [14]. That is, the sensory data are being transformed into entities that we can utilize in our process of problem-solving. Attention comes into play in order to be able to identify what we need and where we need to intervene. "Attention is the process whereby an abundance of stimuli is ordered and integrated within the framework of current tasks and activities: it integrates ongoing activity and newly arriving information. This integration results in the apparent selection of information" [15]. In this regard, sustained attention comes into play, where from all available stimuli, we direct and focus our cognitive abilities to selected ones [16]. Having our attention focused and sustained in order to realize problem-solving, we need to evoke past knowledge and experience from our memory. In particular, our working memory enables us to temporarily store and in turn manipulate all information that we need so as to execute a complex cognitive task [17]. Another process of cognition pertains to reasoning. Broadly defined, reasoning is a process by which we derive conclusions [18]. With regard to problem solving, Newell and Simon [19] in their seminal work proposed that in order to solve a given problem, humans involve a mental representation of an initial state of the problem, a goal state (objective) and the possible intervening states (i.e., the problem space) as well as different strategies for moving through the problem space towards the end goal state (i.e., the search heuristics). Finally, upon the completion of a complex task (e.g., problem solving), the overall output, process, etc. can induce learning, i.e., become new knowledge if the outputs are stored in our long term memory by taking specific paths towards what type of memory is now formed to be saved, i.e., semantic, episodic, procedural, automatic and emotional [20].

Cognitive manufacturing has lately received a lot of attention as a means to enable advanced automation. The concept of the CDT aims at enriching a DT with cognitive capabilities, both internally and through cognitive-capable sensing [21]. Al Faruque et al. [9] presented the abovementioned facets of human cognition as CDT capabilities, envisioning that CDTs enable manufacturing organizations to exploit implicit knowledge drawn from the experience of existing manufacturing systems to improve their performance. Furthermore, in the process of materializing cognitive manufacturing systems, Iarovyi et al. [22] proposed architectures utilizing cognition layers with respective modules in order to allow for the necessary "control loops, decision-making, self-learning, reconfiguration and self-optimization". Mortlock et al. [23] present graph learning as one potential pathway towards enabling cognitive functionalities in manufacturing DTs. An approach for integrating models of human behavior and capacities for security testing with DTs was presented in Becue et al. [7]. Abburu et al. [12] offered a model-driven and data-driven cognitive toolbox focusing on the development of a conceptual architecture including a data ingestion and preparation layer, a model management, a service management and a twin management layer as well as a user interaction layer. Moreover, Zhang et al. [24] discussed how the different levels of self-awareness can be harnessed for the design of CDTs. 
Relevant work has highlighted its benefits through the utilization of DTs in all stages of manufacturing. Indicatively, pertinent to the product design stage, cognition infused in DTs may be utilized towards the searching, sharing and scaling of new potential products [9], paving the way for an abundance of possibilities' examination during new product design stages. Cognitive manufacturing has also been examined also relevant to production and scheduling, where for example a process planning a subsystem in a cognitive manufacturing system needs to have advanced capabilities as understanding design and tolerance requirements, automatic decision making relevant to process measurements and self-adaptation upon unforeseen changes [25]. Another example involves the symbiosis and collaboration between the human operator and the production machines (e.g., manufacturing robots) [26]. An approach for enhancing cognition for DTs in production processes by utilizing services such as modelling, simulation, optimization and knowledge graphs has been provided in Eirinakis et al. [27]. Knowledge graphs (KGs) and artificial intelligence have been proposed to give rise to cognitive capabilities for CDTs $[28,29]$. CDTs have also been proposed for connected and agile supply chains enabling an advanced understanding of failures and trends, the simulation of different scenarios, the prediction of their impact and optimization to derive supply chain-wide solutions [30].

When it comes to resilience, it is a broad term that has been examined widely in manufacturing [31-34]. Resilience is the ability of a manufacturing system to recover from an undesired state and return to its desired state [35]. The overall inherent process complexity and process-to-process interaction dynamics make production processes vulnerable to disturbances of both external (e.g., fluctuation in customer demand, urgent orders, delays of deliveries from suppliers, etc.) and internal nature. In particular, internal disturbances can include (a) planned and, more importantly, unplanned downtime due to a machine damage and need for repair, (b) lack of material or a blockage, (c) speed losses due to ramp-up times' changes, (d) idle running and speed or cycle losses and (e) quality problems where the final product is rejected due to not meeting the quality standards needed [36]. To recover from disturbances and return to normal operation, the production system needs to have properties such as robustness and adaptability, self-regulation and self-discovery, short response time, intelligent components with respective data models, autonomous decision, redundancy and escalation scenarios with simulation [37].

With respect to existing literature, this paper focuses on how the cognitive capabilities of CDTs may be utilized to achieve resilience in production, driven by the corresponding requirements of five real-life industrial cases. Moreover, the current work examines how these capabilities can be materialized via different traditional and contemporary tools, also mapping them to the architecture that ISO 23247 standard offers.

\section{Industrial Production Cases}

In what follows, we present five real-life industrial cases that involve identifying and handling anomalies and events disrupting production processes. These cases stem from an H2020 project named FACTLOG, which envisages the Cognitive Factory in process and manufacturing industries through an ensemble of independent but intertwined DTs coupled with cognitive services which enable them to (i) self-learn, and thus effectively detect and react to anomalies and disruptions but also to opportunities that may arise, (ii) enjoy a local or global view of operations and (iii) be capable for short, mid- and long-term reasoning and optimization. To do so, we have collected requirements from the industrial cases that are examined in this research project to identify the key disruption factors and their respective impacts in production, as denoted by the corresponding stakeholders.

Note that although there is an abundance of potential disruptions in any given industrial setting, the importance in terms of impact or probability in occurring may differ from industry to industry and from factory to factory. In this regard, this paper does not wish to provide an exhaustive enumeration of all possible disruptions that may occur in all possible industries. However, the wide scope of the FACTLOG project has enabled us to collect resilience requirements from (a) diverse industries (oil refineries, waste-to-fuel 
transformation, electronics' production for the automotive industry, steel processing and the textile industry) leading to a breadth in our requirements that includes both process industries and discrete manufacturing as well as (b) leading industrial partners in their respective sectors lending depth in the identified disruptions and the respective impact and subsequent need for resilience through CDTs.

\subsection{Industrial Case Descriptions}

\subsubsection{Oil Refinery: LPG Off-Specs Production Recovery}

In oil refineries, a continuous production of many petroleum products such as LPG, naphtha, gasoline, diesel and fuel oil takes place in a highly intensive energy and utility consumption process. The production plans are prepared by the planning department using computational models to account for the feed capacities of production lines taking under consideration legal specifications for the resulting products $[38,39]$. In parallel to the planning department, the energy department is also involved, as the process is energy intensive in order to optimize energy consumption across the processes. The process of producing LPG from crude oil takes place in different process steps, including processing in Debutanizer, Deetanizer and DEA/Merox columns, SHU units as well as the LPG recovery compressor prior to ending up in an LPG pool. Moreover, each process unit relies on specific settings in order to transform the input to the appropriate output.

LPG off-specs production recovery: The main problem arising in this production process is related to the case where off-specs LPG is produced (i.e., the LPG in the final tank does not adhere to the required specifications). In such a case, the LPG needs to be reprocessed, leading to a huge waste of time, energy and productivity. Hence, the main identified problem in this industrial case is the timely identification or prediction of off-specs LPG production and the subsequent optimal recovery to on-specs production.

\subsubsection{Waste-to-Fuel Transformation: Mitigation of Clogging Problems and New} Feedstock Set-Up

In waste-to-fuel transformer plants, industrial rate machines are utilized to chemically transform organic waste material into high-quality synthetic fuel. Starting from organic waste such as wood, paper, plastics, textile, rubber, etc. in the transformer plant that operates $24 / 7$, synthetic fuel that has a high cetane index, flash point, low sulphur and low clouding point is produced for modern diesel engines and electricity generators or heating. The synthetic fuel is produced through a complex process that consists of feeding, drying, mixing, processing and distilling; the process parameters are heavily dependent on the corresponding raw feedstock.

Mitigation of clogging problems and new feedstock set-up: As the process is continuous, any potential clogging can disrupt the production process by disturbing the process parameters, causing significant time delays and hence reduced productivity. Therefore, there is a need to identify or predict and subsequently mitigate the corresponding clogging problems within the production processes. Additionally, during each time the raw feedstock changes, there is the need to optimally set-up the operational parameters accordingly to the new input materials, which currently is a time-consuming process (from $12 \mathrm{~h}$ to days).

\subsubsection{Automotive Electronics: Production Scheduling with Predictive Maintenance}

In the automotive sector and in particular in the automotive OEM product industry, electronic products such as airbag control units, chaises controllers, hand brake controllers, etc. are designed and produced following strict criteria and high-quality standards for varied final customers with highly different requirements. The production process materializes on different production lines including surface mount technology (SMT) lines, printed circuit board area lines, final assembly and test areas. Then, the finalized products are packaged and shipped. 
Production scheduling with predictive maintenance: In all aforementioned lines, highly automated machines continuously operate and in order to maximize the life-time of the equipment involved in the production process, regular maintenance techniques are performed utilizing valuable information from the involved machines. This information is gathered and interpreted in order to detect failures or defects as early as possible. However, there is still room for improvement towards the alignment of predictive maintenance with the production plan as well as self-diagnosis at the machine level [40-42]. As such, the main problems that were identified are (i) self-diagnosis and predictive maintenance at each machine and (ii) alignment of predictive maintenance with the production plan.

\subsubsection{Steel Processing: Production Scheduling Based on Machine and Crane Performance}

In the Steel processing case, differently shaped bars with 2D or 3D shapes take place within a process that involves cutting and shaping various steel bars of various diameters via automated and manual operations. The connection to the shopfloor is implemented via a rudimentary communications system that allows barcodes to be printed on the shop floor detailing customer orders. From there, on the shopfloor system, there is a continuous laborious process with the steel required for concrete reinforcement transferred via cranes to the required processes and being produced using the operator's knowledge of interpreting the drawings and setting the machines to bend the material to the required specification.

Production scheduling based on machine and crane performance: Within this production environment, the main problems that have been identified are (i) shopfloor visibility in order to collect and analyze data from the involved manufacturing entities (machines and cranes) and, subsequently, (ii) production scheduling optimization taking under consideration the two major identified bottlenecks, machines and cranes, whose performance heavily on the design of the product and the current state of the production site, respectively, while also incorporating malfunction events on those elements [43,44].

\subsubsection{Textile Industry—Production Scheduling with New Orders and Disruptions Caused} by Looms or Yarns

In the textile industry, the process of transforming yarns into fabrics take place in a sequential process from raw material acquisition, storage and inspection to spinning dyeing, weaving, finishing, quality inspection, packaging of the finished product and delivery. Moreover, the textile sector has some inherent peculiarities, such as an extremely high number of product variables, deep customization, a difficulty to predict demand, the length of the production cycle and physical prototyping and sampling, which lead to a very complex production planning process that is highly volatile. As production is exposed daily to changes in production planning to respond to new orders from fashion clothing customers, the constant overlapping of new design sampling and regular production introduces an additional level of complexity to the production planning and scheduling, which needs to face a mass of data hardly manageable by human operators in an efficient way. Additionally, production is also prone to typical disruptions, which are caused by looms malfunctioning or by yarns breaking [45-47].

Production scheduling with new orders and disruptions caused by looms or yarns: Hence, at any given point of production, it may be identified that (i) a loom is malfunctioning/breaks down, (ii) a yarn is broken and requires temporarily halting the machine and repairing the breakage, (iii) a faulty batch of yarns is selected for processing ending up in breakage or (iv) a high priority order arrives that needs to be handled. As such, two main problems have been identified: (i) the identification and evaluation of anomalies on involved manufacturing entities (e.g., looms or yarns) and (ii) production scheduling that optimally introduces changes of order priorities or new orders and stabilizes production by considering disruptions stemming from looms or yarns. 


\subsection{Industrial Case Needs}

In this section, we present the collected needs of the five industrial cases in a unified manner so as to highlight both similarities and differences. Table 1 presents the manufacturing elements involved in each industrial case, the corresponding disruptive events as well as measures that can be taken to alleviate their impact.

Table 1. Manufacturing elements, disruptive events and impact alleviation measures.

\begin{tabular}{|c|c|c|c|c|c|}
\hline & Oil Refinery & Waste-to-Fuel & $\begin{array}{l}\text { Automotive } \\
\text { Electronics }\end{array}$ & Steel Processing & Textile Industry \\
\hline $\begin{array}{c}\text { Involved } \\
\text { manufacturing } \\
\text { elements }\end{array}$ & $\begin{array}{l}\text { Process units, } \\
\text { input feeds and } \\
\text { output tank }\end{array}$ & $\begin{array}{l}\text { Process units } \\
\text { and pipes }\end{array}$ & $\begin{array}{c}\text { Machines and } \\
\text { production lines }\end{array}$ & $\begin{array}{l}\text { Machines and } \\
\text { cranes }\end{array}$ & Looms and yarns \\
\hline Disruptive events & $\begin{array}{l}\text { Anomalies in } \\
\text { process units, } \\
\text { off-specs LPG in } \\
\text { final tank }\end{array}$ & $\begin{array}{l}\text { Clogging in pipes, } \\
\text { new feedstock }\end{array}$ & $\begin{array}{c}\text { Machine } \\
\text { breakdowns and } \\
\text { predictive } \\
\text { maintenance }\end{array}$ & $\begin{array}{l}\text { Machine and crane } \\
\text { malfunctions and } \\
\text { bottlenecks }\end{array}$ & $\begin{array}{c}\text { Machine } \\
\text { malfunctions, yarn } \\
\text { breakage and new } \\
\text { order }\end{array}$ \\
\hline $\begin{array}{c}\text { Impact alleviation } \\
\text { measures }\end{array}$ & $\begin{array}{c}\text { Anomaly } \\
\text { detection, } \\
\text { root-cause and } \\
\text { optimal process } \\
\text { parameters for } \\
\text { on-specs recovery }\end{array}$ & $\begin{array}{l}\text { Clogging detection } \\
\text { and root-cause, } \\
\text { optimized process } \\
\text { parameters for } \\
\text { new raw feedstock }\end{array}$ & $\begin{array}{c}\text { Machine } \\
\text { monitoring and } \\
\text { need for predictive } \\
\text { maintenance, } \\
\text { root-cause and } \\
\text { production } \\
\text { reschedule }\end{array}$ & $\begin{array}{c}\text { Machine and crane } \\
\text { movement } \\
\text { monitoring, } \\
\text { root-cause and } \\
\text { production } \\
\text { reschedule }\end{array}$ & $\begin{array}{c}\text { Machine and yarn } \\
\text { breakage } \\
\text { monitoring, new } \\
\text { orders with } \\
\text { priorities and } \\
\text { production } \\
\text { reschedule }\end{array}$ \\
\hline
\end{tabular}

The underlying fabric of all the industrial cases examined is the need to mitigate the impact of various events and/or anomalies that may disrupt production. To that end, the corresponding industrial case needs have been categorized in terms of

- Real-time monitoring of the production processes and the corresponding manufacturing elements,

- Anomaly detection with respect to the monitored manufacturing elements,

- Root-cause identification focused on the corresponding events that disrupt production,

- Impact assessment of the disruptive events to the current production schedule/plan to evaluate the need for recovery actions,

- Decision support to drive the corresponding recovery actions and

- Evaluation of alternatives to enable informed decision making.

Based on this categorization, Table 2 provides a detailed account of the corresponding needs for each industrial case.

Table 2. Industrial case needs.

\begin{tabular}{cccccc}
\hline & Oil Refinery & Waste-to-Fuel & $\begin{array}{c}\text { Automotive } \\
\text { Electronics }\end{array}$ & Steel Processing & Textile Industry \\
\hline $\begin{array}{c}\text { Real-time } \\
\text { monitoring }\end{array}$ & $\begin{array}{c}\text { Process units and } \\
\text { the final tank }\end{array}$ & $\begin{array}{c}\text { Process units and } \\
\text { pipes }\end{array}$ & $\begin{array}{c}\text { Machines' status } \\
\text { and maintenance } \\
\text { needs }\end{array}$ & $\begin{array}{c}\text { Machines' status } \\
\text { and process times } \\
\text { and crane } \\
\text { movement }\end{array}$ & $\begin{array}{c}\text { Looms' and yarns' } \\
\text { status, new orders } \\
\text { and priorities }\end{array}$ \\
\hline $\begin{array}{c}\text { Anomaly } \\
\text { detection }\end{array}$ & $\begin{array}{c}\text { Anomalies in } \\
\text { process units and } \\
\text { off-specs } \\
\text { production }\end{array}$ & Clogging of pipes & $\begin{array}{c}\text { Machine anomalies } \\
\text { and prediction of } \\
\text { potential failure }\end{array}$ & $\begin{array}{c}\text { Machine } \\
\text { anomalies, } \\
\text { bottlenecks in } \\
\text { cranes' movement }\end{array}$ & $\begin{array}{c}\text { Yarn breakage and } \\
\text { loom stoppage }\end{array}$ \\
\hline $\begin{array}{c}\text { Root-cause } \\
\text { identification }\end{array}$ & $\begin{array}{c}\text { Reason for } \\
\text { off-specs } \\
\text { production }\end{array}$ & $\begin{array}{c}\text { Reason for } \\
\text { clogging }\end{array}$ & $\begin{array}{c}\text { Reason for } \\
\text { potential failure }\end{array}$ & $\begin{array}{c}\text { Reason for } \\
\text { machine } \\
\text { cranction bottleneck }\end{array}$ & $\begin{array}{c}\text { Reason for loom } \\
\text { malfunction and } \\
\text { yarn breakage }\end{array}$ \\
\hline
\end{tabular}


Table 2. Cont.

\begin{tabular}{|c|c|c|c|c|c|}
\hline & Oil Refinery & Waste-to-Fuel & $\begin{array}{l}\text { Automotive } \\
\text { Electronics }\end{array}$ & Steel Processing & Textile Industry \\
\hline $\begin{array}{c}\text { Impact } \\
\text { assessment }\end{array}$ & $\begin{array}{l}\text { Evaluation of } \\
\text { impact of anomaly } \\
\text { to final tank } \\
\text { impurities }\end{array}$ & $\begin{array}{l}\text { Evaluation of } \\
\text { impact of clogging } \\
\text { or new feedstock }\end{array}$ & $\begin{array}{l}\text { Evaluation of } \\
\text { impact of anomaly } \\
\text { or predictive } \\
\text { maintenance }\end{array}$ & $\begin{array}{l}\text { Evaluation of } \\
\text { impact of machine } \\
\text { or crane bottleneck } \\
\text { or malfunction }\end{array}$ & $\begin{array}{c}\text { Evaluation of } \\
\text { impact of machine } \\
\text { malfunction, yarn } \\
\text { breakage, new } \\
\text { orders }\end{array}$ \\
\hline Decision support & $\begin{array}{l}\text { Optimal process } \\
\text { parameters for all } \\
\text { units for on-specs } \\
\text { recovery }\end{array}$ & $\begin{array}{l}\text { Selection of } \\
\text { optimal process } \\
\text { parameters for } \\
\text { new feedstock }\end{array}$ & $\begin{array}{l}\text { Production } \\
\text { reschedule with } \\
\text { machine failures } \\
\text { and predictive } \\
\text { maintenance }\end{array}$ & $\begin{array}{l}\text { Production } \\
\text { reschedule with } \\
\text { actual process } \\
\text { times and } \\
\text { availability of } \\
\text { machines and } \\
\text { cranes }\end{array}$ & $\begin{array}{c}\text { Production } \\
\text { reschedule with } \\
\text { machine failures, } \\
\text { new orders and } \\
\text { priorities }\end{array}$ \\
\hline $\begin{array}{l}\text { Evaluation of } \\
\text { alternatives }\end{array}$ & $\begin{array}{l}\text { Evaluation of } \\
\text { alternative } \\
\text { recovery plans }\end{array}$ & $\begin{array}{c}\text { Evaluation of } \\
\text { alternative process } \\
\text { parameters }\end{array}$ & $\begin{array}{l}\text { Evaluation of } \\
\text { alternative } \\
\text { production } \\
\text { schedules }\end{array}$ & $\begin{array}{l}\text { Evaluation of } \\
\text { alternative } \\
\text { production } \\
\text { schedules }\end{array}$ & $\begin{array}{l}\text { Evaluation of } \\
\text { alternative } \\
\text { production } \\
\text { schedules }\end{array}$ \\
\hline
\end{tabular}

\section{Resilience in Production through Cognitive Capabilities}

As discussed in Section 1, a resilient manufacturing system should have the capability to suffer minimum production loss and recover quickly after each disruption [1]. This is exactly the essence of all five industrial case needs discussed in the previous section, which are focused towards the early detection of disruptions in production and the assessment of their impact, identification of their root-cause (if required) and support in decision making to alleviate their consequences. However, how do these needs correspond to the cognitive capabilities offered by a CDT? Real-time monitoring corresponds to perception, i.e., the organization and interpretation of all sensory input from the environment. Anomaly detection raises attention, but also requires memory that may be induced by learning. Root-cause identification and impact evaluation correspond to reasoning, while decision support and the evaluation of alternatives correspond both to reasoning and problem solving. All four utilize memory and may lead to learning.

Hence, the cognitive capabilities of CDTs can be utilized to support the resilience of production processes. CDTs may incorporate these capabilities through various traditional or contemporary tools and services. For example, perception can be implemented through data analytics on various data streams spanning from sensory data to data drawn from manufacturing or enterprise systems. Attention may be raised by any type of anomaly detection tool, from traditional Statistical Process Control (SPC) or Complex Event Processing (CEP) to even Machine Learning (ML)-based tools, which emulate the behavior of the asset and hence can identify abnormalities. Furthermore, sustained attention can be achieved through, e.g., a controller that, once an anomaly or disruption is detected, drives all actions towards addressing it. Memory in this context refers to production data or domain knowledge. The former (i.e., production data) can be supported from traditional tools such as persistence technologies (e.g., a database). The latter (i.e., domain knowledge) can also be supported by the DT model itself (e.g., in the case of data-driven DT models produced via ML) as well as by a KG model that also enables incorporating contextual information and insights. In this regard, note that model and data-driven DTs may have similar scopes, but their implementation has significant differences. Nevertheless, abstractly, we consider both types of DTs as different implementations of the same concept. The reasoning can be supported by root-cause analysis tools as well as simulations that may enable the assessment of the impact of the detected disruptions. Optimization can be used for obtaining optimal responses to drive recovery from those disruptions, while simulation can be used for evaluating the corresponding alternatives; thus, both can be utilized for 
problem solving. Finally, learning feeds back to the DT model and the corresponding KG models. This mapping from tools to cognitive capabilities towards resilience is presented in Figure 1.

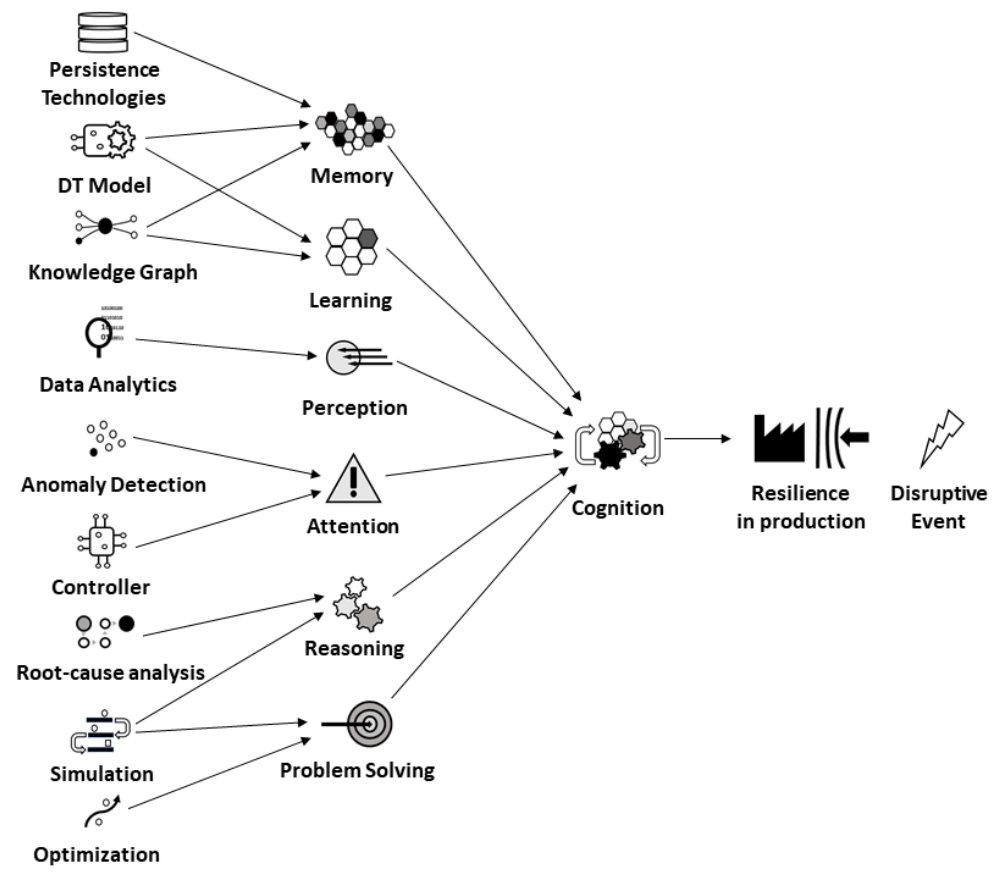

Figure 1. Resilience in production through cognitive capabilities enabled by specific CDT tools and services.

Note that this mapping of tools to cognitive capabilities is indicative and represents the use of the corresponding tools to cover the specific needs of the examined industrial cases. In this regard, the proposed tools may be utilized to also support other cognitive capabilities (e.g., data analytics may be used for reasoning), while other tools (not mentioned here) may also be introduced to cover corresponding industrial needs.

\section{Implementing CDTs for Resilience in Production}

\subsection{Conceptual Architecture}

This section presents a conceptual architecture implementing cognition for DTs. The architecture is based upon the entities and interconnections included in the framework proposed in the ISO 23247 standard. Figure 2 presents the functional view and includes all the components that are required or used along with an indication of the cognition mechanisms and their location in this architecture (in red).

In more detail, the Data collection and Device Control sub-entities are responsible for the direct interaction with the observable manufacturing elements, i.e., the physical assets at site. The DT core entity contains three sub-entities. Two of them are related with cognition, i.e., the Operation $\mathcal{E}$ Management and the Application and Service sub-entities. The Operation and Management consists of the DT model, the KG and the persistence mechanisms. Practically, it includes functionalities related to modelling, knowledge management and storage, which are cognition prerequisites (memory and learning) and relate to cognition management. The second sub-entity contains Application and Service modules. This is where several cognition mechanisms are located, that is, the controller (responsible for processing events and invoking the respective services), data analytics, anomaly detection, simulation, optimization and root-cause analysis. The third sub-entity, i.e., Resource Access and Interchange, is associated with components for granting/denying access, resource identification and data access, synchronization and interoperability. The User Applications entity contains the related UI for dashboards with real time data and alerting along with 
the reporting modules that summarize insightful business-related aggregations. Additionally, the integration of any legacy system and other enterprise systems, such as the manufacturing execution system (MES), enterprise resource planning (ERP) or warehouse management system (WMS), takes place within this entity. The importance of these systems is indisputable, since they can be considered a vital part of the production process. Their inclusion in the architecture at this level implies the implementation of proper APIs able to consume data in a bidirectional manner. Last but not least, the cross-system interface utilizes data assurance and security mechanisms along with a scalable message bus that receives and delivers data in an asynchronous manner to all the involved components from the bottom (physical assets) to the end user via the respective applications.

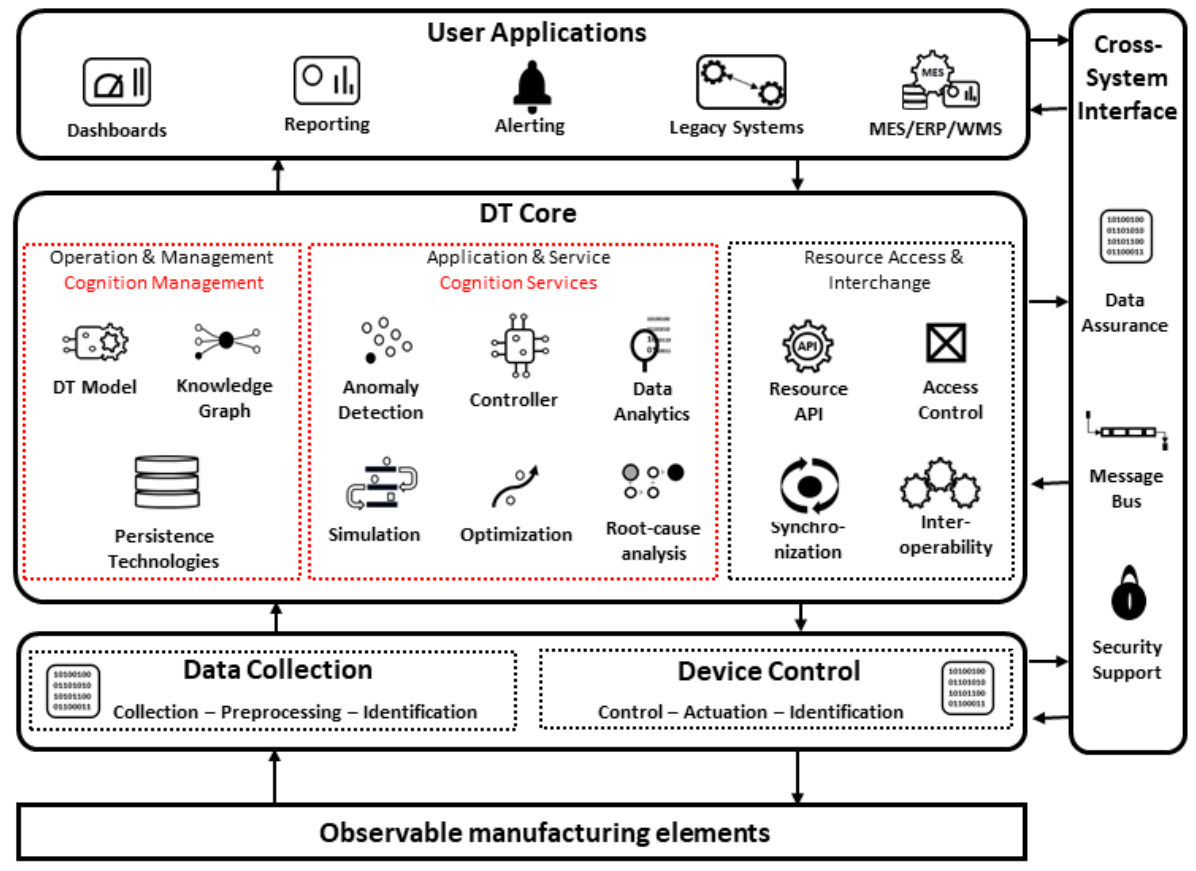

Figure 2. Conceptual architecture.

\subsection{Cognition in the DT Core}

As shown in the previous section, cognition management and services are located in the DT core. Additionally, given the disruption that needs to be handled, there is a plethora of options for cognition services and combinations of them for impact mitigation. Intuitively, the combination of cognition services and management can be modelled as interactions between two or more components of the Operation and Management and the Application and Service sub-entities of the DT core. Figure 3 presents these interactions.

More specifically, cognition components are split into three categories: the knowledge category, which may contain a persistence mechanism (e.g., a database), the DT models (e.g., for data-driven DTs) and the KG models. This is where knowledge is maintained, updated and queried. The Input/Output category refers merely to data related to the input of the problem (e.g., real-time data, historical data, events) or the output of the cognition mechanism. The last category is comprised of all the cognition services located in the DT core which surround the previous two categories.

An interaction between two elements of this diagram (Figure 3) can have two types: (i) A compulsory interaction, depicted as a continuous line, or (ii) an optional interaction, depicted as a hyphenated line. For example, a production line in the manufacturing site may require an anomaly detection mechanism that detects possible machine malfunctions and triggers an optimization algorithm that reschedules the production orders when such a malfunction is identified. This is one approach to such a problem and the main reason we call this interaction between these components optional. Both of these components require 
by default data and possibly domain knowledge. The element that makes compulsory the interaction between a cognition service and a knowledge or input/output component is that cognition services are unable to work without data or domain knowledge. Therefore, we model a cognition mechanism inside the DT core as a set of cognition services and a set of KG models or Input/Output components, which utilize an ordered set of interactions with each other following a very simple rule: This ordered set of interactions starts and ends with a compulsory interaction. Practically, this means that any cognition service utilizes the domain knowledge and the available data, while it returns an output as a result back to the system/end user or new knowledge back to the KG models.

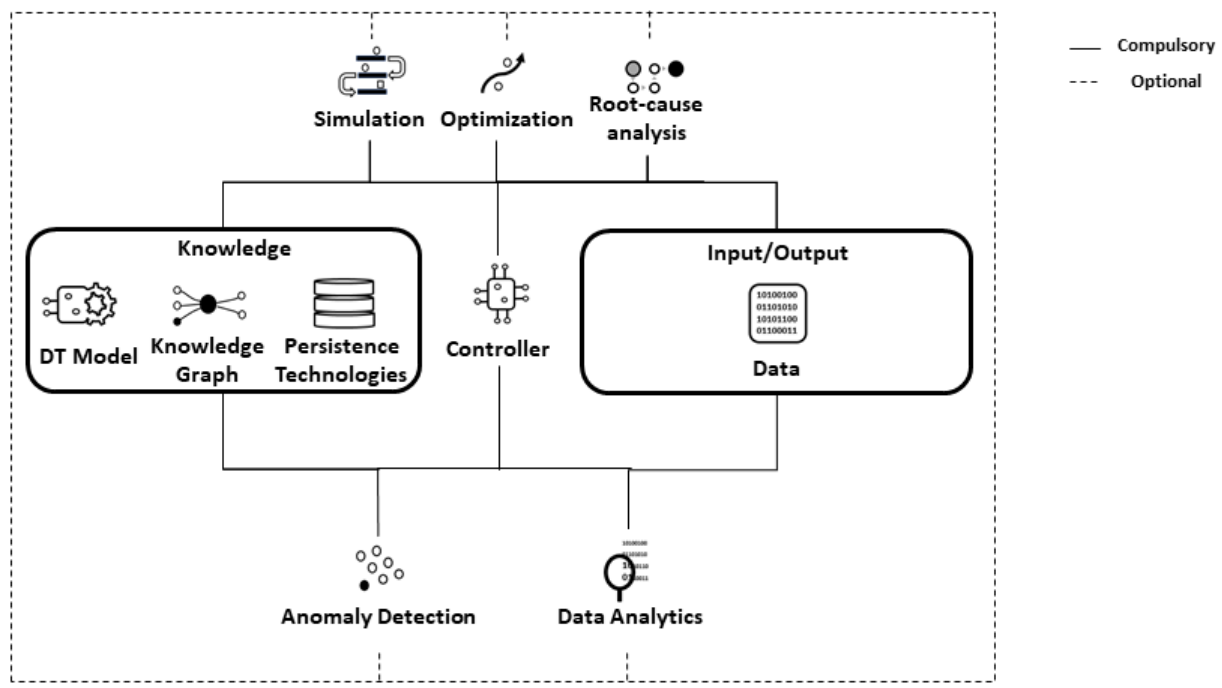

Figure 3. Cognition in the DT core.

\subsection{Pathways to Resilience in Production}

Let us now describe a flow involving several cognition services utilizing the framework of interactions between them as described in the previous section. Suppose that, while monitoring production, an anomaly occurs in a production process. The concept in this scenario is to identify this anomaly early on and to assess the impact of that anomaly for examining whether additional actions are required while, in parallel, performing a root-cause analysis. Given the high-severity status of the impact, the next step is to reoptimize the production schedule and evaluate it together with any other alternatives to identify the best course of action. The services we employ in this instance are data analytics, anomaly detection, the controller, simulation (for impact assessment), root-cause analysis, optimization and then again simulation (for evaluation of alternatives). Figure 4 presents the sequence of the involved services along with their mapping with the respective cognitive capability.

More specifically, as data arrive in the input, data analytics is used to perceive the situation. Anomaly detection identifies suspicious patterns in the situation and draws attention to them. Then it informs the controller to sustain this attention, driving any required actions from this point on. The controller invokes root-cause analysis and simulation. Both of these services perform reasoning on the situation towards two directions. Root-cause analysis identifies the main cause of this anomaly. Simulation at this stage assesses the impact of the anomaly. If the impact is considerable, then we need to address the problem of re-optimizing the production schedule. Once this is complete, an extra problem needs to be solved, i.e., the evaluation of alternatives, which is performed via simulation. At any point, decisions taken by any cognitive service are based on knowledge that is maintained in the DT-model, the KG models or the persistence mechanism. Finally, the knowledge stored in these components can be updated with new findings and results from the cognitive services. 


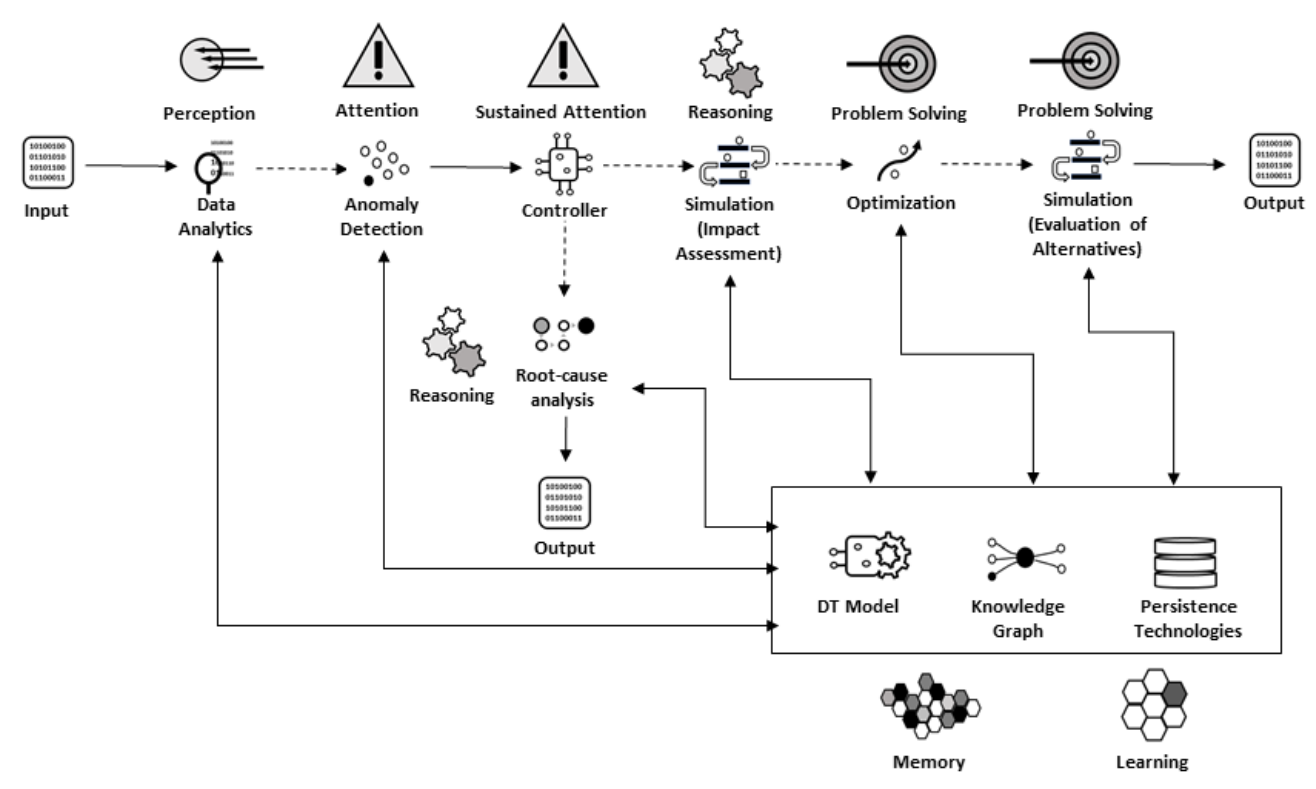

Figure 4. Paths to resilience and cognitive services.

\section{Discussion}

The cognitive process may take different paths and utilize different capabilities in the process of handling disruptions. However, a prerequisite of cognition is having sensorial input points on the physical manufacturing elements coupled with services enabling data ingestion and cleaning. These tools are included in the Data Collection sub-entity of the conceptual architecture provided in Figure 2. Perception may then include stream analytics or even predictive analytics on the incoming data. Following perception, and upon an out-of-ordinary sensorial input, attention comes into play in order to initially pinpoint the actual sensorial input that signifies the need for the system to direct its focus into a specific virtual twin (and thus physical asset). This attention then needs to be sustained; in this regard, a controller may come into play, being responsible to invoke the appropriate tools and services and orchestrate the data transference between them. Throughout this cognitive process and at any step, memory (inherent within the DT model, the KG and persistence) can be invoked. Having all information available enables reasoning, where interpretation takes place on different levels, with the main goal being to properly understand the causes and effects of this new situation by drawing meaningful conclusions. The next process is problem solving, where different courses of action may be produced and evaluated towards selecting the most appropriate. Lastly, and upon successful problem solving and returning to normality (or not), the final process is learning, derived from the conducted cognition cycle. In this process, the DT model or the KG may come again into play for codifying and maintaining the newly produced knowledge.

Note that the use of a controller is not necessary to sustain attention towards handling a detected disruptive event; it merely provides a centralized management of action to the corresponding CDT. Decentralized implementations could also be considered, where each tool incorporates its part in handling the disruption, incorporates part of the logic involved and invokes in turn the tools (cognitive capabilities) that are required next to tackle the issue at hand. In such cases, sustained attention would become a decentralized matter; however, the centralized approach enables a more modular, service-based architectural approach.

The implementation of the services and tools that materialize the cognitive capabilities of CDTs may also differ significantly with respect to the corresponding manufacturing setting, the specificities of the production processes and the nature of the disruptive events that need to be handled. Let us consider, for example, the approach that can be taken for each one of the industrial cases discussed in Section 3 with respect to optimization. Typically, mixed integer linear programming (MILP) can be utilized in several production 
settings. For instance, in the LPG off-specs recovery case, MILP can be used to enable defining both decisions on unit process parameters and the flow of LPG, together with constraints that model the blending process and others that define the specification levels, etc. Optimality in this setting requires producing a plan for recovery to on-specs production within a given time horizon while minimizing energy consumption. MILP can also be typically used in the steel processing case, where the model may need to take into account machine-dependent setup times and processing speeds in each stage as well as lag times between the processes of two consecutive stages while also taking into account the movement of cranes, with the objective function being makespan, tardiness or a combination of these two. However, dynamic programming [48] and heuristics [49] have also been suggested to model the movement of factory cranes. The weaving process of the textile industry can also be modeled via MILP, which handles critical job and machine properties such as job splitting (where each orders' quantity can be split and processed on multiple machines), sequence-dependent setup times and setup resource constraints (e.g., the number of available workers constraints the number of machine setups that can be performed simultaneously). For larger instances, however, heuristics can also be applied both for job-splitting and the assignment of jobs to machines. On the other hand, simulation-based optimization can be utilized to support a complex, stochastic and multi-stage process, such as waste-to-fuel transformation. A Constraint Programming (CP) approach can be utilized for the automotive electronics case, where the objective is to reschedule production by incorporating preventive maintenance activities while also taking into account resource constraints (in terms of semi-finished products, raw materials, etc.). CP may be selected for this case to handle the size of the problem (i.e., number or machines, production lines, products, resources, etc.) and the interconnection between the different production operations and resources.

\section{Conclusions and Future Research}

This paper presented how the cognitive capabilities inherent in a CDT can be utilized to support the resilience of production processes, i.e., enabling a manufacturing system to detect and to handle events that may disrupt production and to absorb and alleviate the corresponding consequences. Five cases have been presented stemming from different industries, having similarities but also significant differences in production processes as well as the type of disruptions they need to handle. In this regard, a common set of needs has been provided in terms of real-time monitoring, anomaly detection, root-cause identification, the assessment of the impact of a disruptive event, decision support and the evaluation of alternatives. These needs have been mapped to specific cognitive capabilities that can cover them and, accordingly, to tools that can materialize them within CDTs. A conceptual architecture based upon the entities inherent in the ISO 23247 framework for DTs has also been provided, placing the tools that materialize cognition within the DT core. Further, a cognition process that utilizes the cognitive capabilities of CDTs to offer pathways for addressing disruptive events in production has been presented.

Future research includes examining the interplay between the specific tools developed for each case giving rise to the cognitive capabilities of CDTs and validating the proposed approach in real-life instances towards achieving resilience in production. The goal will be to showcase the additive value of the proposed cognitive process as a whole in alleviating the consequences of disruptive events as compared with the way each manufacturing system would actually handle them without CDTs or if each proposed tool was used on its own.

Author Contributions: Conceptualization, P.E., S.L., S.P., G.A., K.K. (Kostas Kalaboukas), K.K. (Klemen Kenda), J.L., J.M.R. and N.S.; Data curation, P.E., S.L., S.P., G.A., K.K. (Kostas Kalaboukas), K.K. (Klemen Kenda), J.L., J.M.R. and N.S.; Formal analysis, P.E., S.L. and S.P.; Funding acquisition, P.E., S.L., G.A., K.K. (Kostas Kalaboukas) and N.S.; Investigation, P.E., S.L., S.P., G.A., K.K. (Kostas Kalaboukas), K.K. (Klemen Kenda), J.L., J.M.R. and N.S.; Methodology, P.E., S.L. and S.P.; Project administration, P.E. and S.L.; Resources, P.E., S.L., S.P., G.A., K.K., K.K., J.L., J.M.R. and N.S.; Software, 
P.E., S.L., S.P., G.A., K.K. (Kostas Kalaboukas), K.K. (Klemen Kenda), J.L., J.M.R. and N.S.; Supervision, P.E.; Validation, P.E., S.L., S.P., G.A., K.K. (Kostas Kalaboukas), K.K. (Klemen Kenda), J.L., J.M.R. and N.S.; Visualization, P.E. and S.P.; Writing-original draft, P.E., S.L. and S.P.; Writing-review and editing, G.A., K.K. (Kostas Kalaboukas), K.K. (Klemen Kenda), J.L., J.M.R. and N.S. All authors have read and agreed to the published version of the manuscript.

Funding: This research was funded by the H2020 FACTLOG project, which has received funding from the European Union's Horizon 2020 programme under grant agreement No. 869951.

Data Availability Statement: Not applicable.

Conflicts of Interest: The authors declare no conflict of interest.

\section{References}

1. Gu, X.; Jin, X.; Ni, J.; Koren, Y. Manufacturing system design for resilience. Procedia CIRP 2015, 36, 135-140. [CrossRef]

2. Eirinakis, P.; Kasapidis, G.; Mourtos, I.; Repoussis, P.; Zampou, E. Situation-aware manufacturing systems for capturing and handling disruptions. J. Manuf. Syst. 2021, 58, 365-383. [CrossRef]

3. Tao, F.; Zhang, H.; Liu, A.; Nee, A.Y. Digital twin in industry: State-of-the-art. IEEE Trans. Ind. Inform. 2018, 15, 2405-2415. [CrossRef]

4. Cimino, C.; Negri, E.; Fumagalli, L. Review of digital twin applications in manufacturing. Comput. Ind. 2019, 113, 103-130. [CrossRef]

5. Liu, M.; Fang, S.; Dong, H.; Xu, C. Review of digital twin about concepts, technologies, and industrial applications. J. Manuf. Syst. 2021, 58, 346-361. [CrossRef]

6. Grieves, M. Digital Twin: Manufacturing Excellence through Virtual Factory Replication; White Paper; Florida Institute of Technology: Melbourne, FL, USA, 2014; Volume 1, pp. 1-7.

7. Becue, A.; Maia, E.; Feeken, L.; Borchers, P.; Praca, I. A new concept of digital twin supporting optimization and resilience of factories of the future. Appl. Sci. 2020, 10, 4482. [CrossRef]

8. Tao, F.; Zhang, M.; Cheng, J.; Qi, Q. Digital twin workshop: A new paradigm for future workshop. Comput. Integr. Manuf. Syst. 2017, 23, 1-9.

9. Al Faruque, M.A.; Muthirayan, D.; Yu, S.Y.; Khargonekar, P.P. Cognitive Digital Twin for Manufacturing Systems. In Proceedings of the 2021 Design, Automation \& Test in Europe Conference \& Exhibition, Grenoble, France, 1-5 February 2021; pp. 440-445.

10. Kritzinger, W.; Karner, M.; Traar, G.; Henjes, J.; Sihn, W. Digital Twin in manufacturing: A categorical literature review and classification. IFAC-PapersOnLine 2018, 51, 1016-1022. [CrossRef]

11. International Organization for Standardization. Automation Systems and Integration-Digital Twin Framework for Manufacturing (ISO Standard 23247-1:2021). 2021. Available online: https://www.iso.org/standard/75066.html (accessed on 30 December 2021).

12. Abburu, S.; Berre, A.J.; Jacoby, M.; Roman, D.; Stojanovic, L.; Stojanovic, N. COGNITWIN-Hybrid and cognitive digital twins for the process industry. In Proceedings of the 2020 IEEE International Conference on Engineering, Technology and Innovation (ICE/ITMC), Cardiff, UK, 15-17 June 2020; IEEE: Piscataway, NJ, USA, 2020; pp. 1-8.

13. Li, Y.; Chen, J.; Hu, Z.; Zhang, Z.; Lu, J.; Kiritsis, D. Co-simulation of complex engineered systems enabled by a cognitive twin architecture. Int. J. Prod. Res. 2021. [CrossRef]

14. Huffman, K.; Dowdell, K.; Sanderson, C.A. Psychology in Action; John Wiley \& Sons: Hoboken, NJ, USA, 2017.

15. Phaf, R.H.; Van der Heijden, A.H.C.; Hudson, P.T. SLAM: A connectionist model for attention in visual selection tasks. Cogn. Psychol. 1990, 22, 273-341. [CrossRef]

16. DeGangi, G.; Porges, S. Neuroscience Foundations of Human Performance; American Occupational Therapy Association Inc.: Rockville, MD, USA, 1990.

17. Baddeley, A.D.; Hitch, G. Working memory. In Psychology of Learning and Motivation; Academic Press: Cambridge, MA, USA, 1974; Volume 8, pp. 47-89.

18. Leighton, J.P. Defining and Describing Reason. In The Nature of Reasoning; Leighton, J.P., Sternberg, R.J., Eds.; Cambridge University Press: Cambridge, UK, 2004; pp. 3-11.

19. Newell, A.; Simon, H.A. Human Problem Solving; Prentice-Hall: Hoboken, NJ, USA, 1972.

20. Sprenger, M. Learning and Memory: The Brain in Action; Association of Supervision and Curriculum Development: Alexandria, VA, USA, 1999; ISBN 0-87120-350-2.

21. Saracco, R. Digital twins: Bridging physical space and cyberspace. Computer 2019, 52, 58-64. [CrossRef]

22. Iarovyi, S.; Lastra, J.L.M.; Haber, R.; del Toro, R. From artificial cognitive systems and open architectures to cognitive manufacturing systems. In Proceedings of the 2015 IEEE 13th International Conference on Industrial Informatics (INDIN), Cambridge, UK, 22-24 July 2015; pp. 1225-1232.

23. Mortlock, T.; Muthirayan, D.; Yu, S.Y.; Khargonekar, P.P.; Faruque, M.A.A. Graph Learning for Cognitive Digital Twins in Manufacturing Systems. arXiv 2021, arXiv:2109.08632. [CrossRef] 
24. Zhang, N.; Bahsoon, R.; Theodoropoulos, G. Towards Engineering Cognitive Digital Twins with Self-Awareness. In Proceedings of the 2020 IEEE International Conference on Systems, Man, and Cybernetics (SMC), Toronto, ON, Canada, 11-14 October 2020; IEEE: Piscataway, NJ, USA, 2020; p. 3891.

25. Zhao, Y.F.; Xu, X. Enabling cognitive manufacturing through automated on-machine measurement planning and feedback. Adv. Eng. Inform. 2010, 24, 269-284. [CrossRef]

26. Li, S.; Wang, R.; Zheng, P.; Wang, L. Towards proactive human-robot collaboration: A foreseeable cognitive manufacturing paradigm. J. Manuf. Syst. 2021, 60, 547-552. [CrossRef]

27. Eirinakis, P.; Kalaboukas, K.; Lounis, S.; Mourtos, I.; Rožanec, J.M.; Stojanovic, N.; Zois, G. Enhancing cognition for digital twins. In Proceedings of the 2020 IEEE International Conference on Engineering, Technology and Innovation (ICE/ITMC), Cardiff, UK, 15-17 June 2020; IEEE: Piscataway, NJ, USA, 2020; pp. 1-7.

28. Lu, J.; Zheng, X.; Gharaei, A.; Kalaboukas, K.; Kiritsis, D. Cognitive Twins for Supporting Decision-Makings of Internet of Things Systems. In Proceedings of the 5th International Conference on the Industry 4.0 Model for Advanced Manufacturing. Lecture Notes in Mechanical Engineering; Wang, L., Majstorovic, V., Mourtzis, D., Carpanzano, E., Moroni, G., Galantucci, L., Eds.; Springer: Cham, Switzerland, 2020. [CrossRef]

29. Rožanec, J.M.; Lu, J.; Rupnik, J.; Škrjanc, M.; Mladenić, D.; Fortuna, B.; Kiritsis, D. Actionable Cognitive Twins for Decision Making in Manufacturing. arXiv 2021, arXiv:2103.12854. [CrossRef]

30. Kalaboukas, K.; Rožanec, J.; Košmerlj, A.; Kiritsis, D.; Arampatzis, G. Implementation of Cognitive Digital Twins in Connected and Agile Supply Networks-An Operational Model. Appl. Sci. 2021, 11, 4103. [CrossRef]

31. Zhang, W.J.; Van Luttervelt, C.A. Toward a resilient manufacturing system. CIRP Ann. 2011, 60, 469-472. [CrossRef]

32. Wang, J.; Muddada, R.R.; Wang, H.; Ding, J.; Lin, Y.; Liu, C.; Zhang, W. Toward a resilient holistic supply chain network system: Concept, review and future direction. IEEE Syst. J. 2014, 10, 410-421. [CrossRef]

33. Mourtzis, D.; Angelopoulos, J.; Panopoulos, N. Robust Engineering for the Design of Resilient Manufacturing Systems. Appl. Sci. 2021, 11, 3067. [CrossRef]

34. Kusiak, A. Fundamentals of smart manufacturing: A multi-thread perspective. Annu. Rev. Control 2019, 47, 214-220. [CrossRef]

35. Hollnagel, E.; Woods, D.D.; Leveson, N. Resilience Engineering: Concepts and Precepts; Ashgate Publishing, Ltd.: Farnham, UK, 2006.

36. Ingemansson, A.; Bolmsjö, G.S. Improved efficiency with production disturbance reduction in manufacturing systems based on discrete-event simulation. J. Manuf. Technol. Manag. 2004, 15, 267-279. [CrossRef]

37. Galaske, N.; Anderl, R. Disruption Management for Resilient Processes in Cyber-Physical Production System. Procedia CIRP 2016, 50, 442-447. [CrossRef]

38. Abdullah, Z.; Norashid, A.; Zainal, A. Nonlinear modelling application in distillation column. Chem. Prod. Process Model. 2007, 2. [CrossRef]

39. Ramli, N.; Hussain, M.A.; Jan, B.M.; Abdullah, B. Composition Prediction of a Debutanizer Column using Equation Based Artificial Neural Network Model. Neurocomputing 2014, 131, 59-76. [CrossRef]

40. Giobergia, F.; Baralis, E.; Camuglia, M.; Cerquitelli, T.; Mellia, M.; Neri, A.; Tricarico, D.; Tuninetti, A. Mining Sensor Data for Predictive Maintenance in the Automotive Industry. In Proceedings of the IEEE 5th International Conference on Data Science and Advanced Analytics (DSAA), Turin, Italy, 1-3 October 2018; pp. 351-360. [CrossRef]

41. Einabadi, B.; Baboli, A.; Ebrahimi, M. Dynamic Predictive Maintenance in industry 4.0 based on real time information: Case study in automotive industries. IFAC-PapersOnLine 2019, 52, 1069-1074. [CrossRef]

42. Theissler, A.; Pérez-Velázquez, J.; Kettelgerdes, M.; Elger, G. Predictive maintenance enabled by machine learning: Use cases and challenges in the automotive industry. Reliab. Eng. Syst. Saf. 2021, 215, 107864. [CrossRef]

43. Yuan, F.; Feng, K.; Lin, S.; Xu, A. A study on DAA-based crane scheduling models for steel plant. Int. J. Prod. Res. 2021, 59, 6241-6251. [CrossRef]

44. Fanti, M.P.; Iacobellis, G.; Rotunno, G.; Ukovich, W. A simulation based analysis of production scheduling in a steelmaking and continuous casting plant. In Proceedings of the 2013 IEEE International Conference on Automation Science and Engineering (CASE), Madison, WI, USA, 17-20 August 2013; IEEE: Piscataway, NJ, USA, 2013.

45. He, W.; Meng, S.; Wang, J.; Pan, R.; Gao, W. Weaving scheduling based on an improved ant colony algorithm. Text. Res. J. 2021, 91, 543-554. [CrossRef]

46. Mahmood, A. Smart lean in ring spinning-A case study to improve performance of yarn manufacturing process. J. Text. Inst. 2020, 111, 1681-1696. [CrossRef]

47. Serafini, P.; Grazia Speranza, M. Production scheduling problems in a textile industry. Eur. J. Oper. Res. 1992, 58, 173-190. [CrossRef]

48. Aron, I.D.; Genç-Kaya, L.; Harjunkoski, I.; Hoda, S.; Hooker, J.N. Factory crane scheduling by dynamic programming. In Proceedings of the 12th INFORMS Computing Society Conference, Monterey, CA, USA, 9-11 January 2011. [CrossRef]

49. Peterson, B.; Harjunkoski, I.; Hoda, S.; Hooker, J.N. Scheduling multiple factory cranes on a common track. Comput. Oper. Res. 2014, 48, 102-112. [CrossRef] 